\title{
THE PLACE OF ECONOMIC THEORY IN GRADUATE WORK
}

The very words of this topic are provocative. We are invited to consider the place of economic theory in graduate work. Here at the outset is the implication that in a general scheme of advanced economic study theory is to occupy a place somewhat apart. A distinction is, in effect, drawn for us between economic theory and ordinary economics.

If this suggested distinction were merely the mishap of a phrase it would be trivial to notice it. But in fact it accords closely with a good deal of our academic practice, and finds colloquial expression in our departmental discussions. We organize and announce separate courses in "theory." We require a specialist in "theory" as one member of a well-balanced economic staff. We are asked to recommend "a man in theory" to fill a vacant chair. We intrust "practical" courses to teachers who lack both inclination and capacity for "theoretical" instruction. We remark a bent toward theory in certain of our graduate students and an inaptitude for theory in others - thus ourselves raising, more or less superficially, the question that is here raised for us: What, after all, is the proper place of theory in the general plan of graduate instruction?

Now, of course, this prevalent view of the subject has its reasons and in some degree its justification. Undeniably, there are recognizable and proper differences in the stage of abstraction to which our several economic inquiries are pursued. But we have allowed these differences of degree and extent to grow into supposedly important differences of kind, with results which are unfortunate alike for economic theory and for the impliedly non-theoretical economics. In consequence we habitually set off economic theory as a distinct branch of our subject; we identify it to a regrettable extent with the more or less conventionalized theory of value and distribution; and, attributing to economic theory, thus conceived, a 
peculiar and essential virtue akin to authority, we impose it upon the student in that pious spirit. With all these practices I take issue.

The word "theory" has come to have a double meaning. By its derivation, the theorist is the onlooker who sees comprehensively and with inward reflection. Theory thus becomes the generalized interpretation of fact-the reasoned scheme which fits the array of facts and gives them relation and meaning. But such generalization has been misunderstood and misrepresented. To the common mind, distrustful of abstractions, theory, since it is distinct from specific and concrete fact, seems necessarily the opposite of fact, and thus the antithesis of reality. Theory becomes fantastic, visionary, not to be taken seriously. The plain, everyday world seems to have no place for it. In fine, it is a term of disparagement.

This ambiguity of meaning seems to have embarrassed a good many of the economists. They recognize, somewhat perfunctorily, the importance and dignity of scientific generalization. They vaguely perceive that an abstract principle, reasonably consistent with all the known evidence, is, in a very real sense, truer than the single, incomplete, and perhaps unrepresentative impression which we call a fact. But at the same time they find any departure from fact disconcerting. Economics deals, supposedly, with very practical matters and appeals to practical people. If it is once branded as theory it loses touch with the business man's world of industry and trade. So, believing in theoretical economics, yet fearing to compromise the reputation of economics as a study of affairs, the perplexed economists contrive to separate the two. In the outcome we find economic theory enshrined apart and regarded with perhaps more veneration than intelligence.

Here a new complication arises. Theory, held aloof and cut away from the contacts that make for change, acquires a prestige of tradition. Already remote from its factual data as a result of extreme abstraction, it now becomes remote in time as well; but what it loses in reality it is supposed more than to regain in authority. However much a practical modern student may hesitate to stray from his facts, the case looks different when the straying has 
been done by several successive generations of distinguished thinkers. Under these impressive auspices, moreover, we are inclined to forget, except in our most irreverent moments, that the empirical foundations of the classical system of economics were probably never what we should now call critically valid scientific data. Yet in the old days, quite as much as now, what passed for objective fact must have been largely dogma or partisan opinion. Indeed, thè notion of historical relativity has latterly accustomed us to read between the lines of English economics, for example, the politics of merchant princes, the complaints of poor-rate payers, the differences between landed proprietors and a newly risen industrial bourgeoisie. Hence, to the extent to which we attribute greater objectivity to contemporary scientific observations we must be uneasily conscious that our theoretical heirlooms do not stand on quite the same ground with more recent studies. If both are to be retained, each must have its separate justification. Again the line of demarkation is drawn; and traditional theory is preserved in a place of its own, partly from inertia, partly through vague respect for authority, and partly because we feel that the older views, whatever their original basis may have been, are now so far purified by much dialectical refinement as to have a peculiar claim to our allegiance.

In a measure, no doubt, it is true that the long-continued process of intellectual sublimation has translated orthodox economics from rough empiricism toward the sphere of so-called first principles. If that is the case, and if first principles reflect the more or less fixed conditions and laws of human thought, it will follow that the correctness of our extreme economic abstractions cannot very well be disproved. The superior expediency of such rarefied thought is nevertheless questionable. In terms of first principles, all branches of thought approach a limiting unity and lose their particular characteristics. But the economics which most of us believe in has a fairly well-identified place in a field of fairly tangible information. The most useful plane for economic theorizing is neither on the surface-level of fact nor at the depth of first principles. It lies somewhere between. There theory in its more robust sense organizes, relates, and interprets the material of our observation. 
It is the systematic framework that articulates detailed descriptive knowledge. And it tests its validity by the degree to which it informs with general meaning the aggregate of our concrete experiences of mankind getting a living in modern society.

If, then, theory be thus vigorously interpreted as the organization of scientific knowledge, it is, beyond all dispute, vital in the field of economics. Economics is theory of just this sort. The name economics cannot rightly be applied to bare, disorganized observations of the phenomena of industrial society. On the other hand, it is wasted if it is made to refer exclusively to the impalpable substance of abstruse reflection.

It has not been my intention, in what has preceded, to argue that the university curriculum has no place for an essentially detached study of abstract economic theory. I do maintain that the importance of traditional theory is commonly overrated, and that there is economic theory of a different and far more indispensable sort. But before this point is further elaborated it will be well to notice a phase of our topic that has thus far been neglected. We are inquiring what is the proper place of theory in graduate work. Let us consider a moment what results graduate work is meant to accomplish and how these results may best be attained.

Roughly, our graduate curriculum has three chief ends in view. We strive to equip teachers; to impart learning, and thus foster scholarship in the sense of erudition; and, finally, to train for original investigation and research. As the course of study for the doctorate is ordinarily organized, these purposes are confused to an extent not at all creditable to the clearness of our thinking; for the objects sought are not necessarily identical, nor even quite consistent. The man who has written a monograph in an unexplored field may be perfectly unqualified to teach. The scholar, drenched in the literature of his subject, may have power neither to add to it nor even to make it effectually known to others. For the present occasion, let us take up the several ends of graduate study separately.

The teacher's training must depend very largely upon what he is expected to teach. Logically, there would seem to be no reason to train teachers of a subject that does not commend itself 
as worth teaching. Practically, teachers are produced to suit the demand of the market. Pedagogical technique apart, if the teacher is required to teach old-line theory, he must have been taught oldline theory. If he is to guide students in research, he must understand the method and spirit of research. This, however, as will shortly be urged, implies a grasp of essential theory in the truest and best sense.

To the man learned in economics nothing economic is alien. Old ideas and new, accepted views and rejected fallacies, pure theory and concrete fact - all fall into place in his scheme, properly enough, if they have had their place in the history of economic thought. So long as scholarship for scholarship's sake-as a passion of the intellect - is held to be a just object of attainment, so long each item of interest will have its own justification. The economic antiquarian and savant is as worthy of respect as any other. But because all economic knowledge is properly his, he can hardly stand as the sponsor of any one special branch of it.

It is the investigator, the constructive scholar, who seems to stand out in our minds as the special end and aim of graduate training. The usual specifications for the Doctor's degree show this emphasis clearly enough. We wish our trained economist not merely to absorb, or to transmit, but to enlarge our knowledge of the economic conditions of life. Even if much of his career is to be spent in teaching, he still must have the disciplined power of discovery. What, then, has the study of theory to offer to him?

From the first, he must see phenomena in terms of their significant relationships. Lacking ability thus to relate, systematize, interpret, he is no true economist, but at best only an economist's helper, whose labors avail little unless they are performed under the direction of the more highly skilled worker who has the judgment to put each detail in its due place. But to see facts in their larger, more general aspects is to theorize. Only the sound theorist can be the sound investigator, and only the sound investigator can deepen our understanding of economic principles in the long run.

It will be apparent that the term "theory" is here used to cover both the concept of a right method of investigation and the refined and generalized conclusions which grow from scientifically gathered 
data. Theory and method do indeed blend together. In the present context, however, method is the more emphasized. The question will therefore arise: How otherwise is a correct method to be acquired than by faithful study of the examples of economic inquiry which have come down to us?

Clearly there is no occasion to depreciate the importance of a critical acquaintance with the best previous economic thinking. There are, however, several reasons to protest against attributing unique and exclusive authority to so-called theoretical economics of the past. First, in any branch of knowledge that is to live and grow, past achievements are not so much patterns for later work as points of departure. This granted, it is next to be insisted that in learning from past achievements we must consult for our guidance, not merely abstract works on economic theory and methods, but the examples of theory and method embodied in the more concrete economic investigations. Nor is this enough. Not even the whole range of the older economics will suffice as the basis of economics in the future. The modern economist must draw suggestion from other sources of thought, and borrow new methods, new standards of scientific technique, wherever they are to be found and adapted.

The prevalent usage of our academic routine introduces the undergraduate to the economic domain through the gateway of orthodox theory. ${ }^{x}$ The theoretical discipline of the introductory course is often mild, to be sure, and the theoretical content eclectic, scattered, or even contradictory. Nevertheless, the ordinary procedure has been to inculcate certain accepted generalizations or principles before admitting the student to the more factual and descriptive courses in economics; and here again a virtual antithesis between theoretical foundation and "applied" or "practical" superstructure has doubtless widened the implicit gulf between economic theory and the rest of economics. The word "applied" itself, in this connection, hints of such a false antithesis, for it suggests that the evidence presented in specialized courses

I This practice, fortunately, is becoming far less universal than it was. More enlightened methods of elementary economic instruction, and especially emphasis upon the development of economic institutions, have already effected an important change for the better. 
must be made to fit the preconceptions of some previously promulgated theory. However, if, despite this handicap, the student's "practical" courses convince him that he is interested in economics, and if, accordingly, he enters upon graduate work, again he is met at or near the threshold with a requirement of theoretical tasks to be performed before his more individual and original studies are undertaken. Thus the course to the doctorate is stratified - theory and application, theory and application; and in each pair of strata, theory, in time or in emphasis, comes first. The output of such a system will in the main be an output of conformists. Some students will, of course, become radicals through revolt. More, perhaps, will simply be lost to economics by disaffection. The majority will be economists of sorts, creditable on the whole, safe, sane, and unoriginal. Their drill has been such as to assure them against going far off the path. But their chances of going splendidly right in the direction of originality and creative thought would have been better if their training had been less pervaded by the spirit of authority.

Contemporary economics needs to beware of ex-cathedra doctrine. The distinction between scholarship and scholasticism did not cease with the Middle Ages. Thought has flowed on for a few centuries, and we recognize now what was then current and what was stagnation. But the stream still flows; and even contemporary judgment occasionally suspects that some of our present-day theoretical disputations and formulations of economic systems are thoughts caught in the eddies or lodged in slack water. Moreover, the stream of economic ideas descends from no one fountain head. It has been swelled and freshened from innumerable sources since the day of Adam Smith. And in so far as we are to be guided by tradition in our economic theorizing we must still expect to find a part of our tradition in the many sciences which our broadening view discloses as tributary to economics. They offer us new evidence, new methods, and the stimulating suggestion that comes from a mingling of hitherto separate ideas.

Fifty years from now much of what is best in the economics of that period will unquestionably be traceable to men and materials outside of the present conventional economic pale. Of the coming 
generation of economists not all are now professedly or consciously students of economics. Some are students in neighboring departments of academic discipline; others are intelligent workers outside the academic circle. Nor is it likely that these as yet unrevealed economists will prove to be less significant and original than their fellows whose predetermined careers are now taking shape in the accepted groove of economic instruction.

If this prediction seems reasonable, then it must be conceded that the economic-theory courses of our universities are not the single road to achievement in economics. One is tempted to take a further step and ask whether early and rigorous drill in orthodox economic theory is necessarily the only fit training for the academic student of economics. Is it not possible that he also may find elsewhere an equivalent discipline in scientific inference, perhaps a greater stimulus to fresh and original economic thinking, and at least an escape from the imposition of authoritative forms of thought until individuality and initiative in thought have been somewhat established? For my own part, I should have great hopes of the economist whose beginnings had been made in the critical and intelligent study of social psychology, or of ethnology, or of institutional history, or of the law of public-service corporations, or of industrial engineering. When later some economic problem arrested his attention, it might stand out all the more sharply because of the half-contrasting background of his earlier intellectual experience. His analysis might be vivid and novel; and if his critical sense, in whatever branch of science acquired, were well enough developed to keep him from being too erratic, he could in due course enter upon a formal economic training with much to gain and little to lose by contact with its formality. Of course, not everyone so evolved makes an economist, but when an economist does thus arise he is likely to bring a message for the science.

Particularly auspicious among these ancillary fields of training are statistics and the scientific study of so-called commercial subjects. Statistical method and economic method are pretty certainly destined to have more and more in common. Already statistics is the point of contact between the subject-matter of the social sciences and the newer logic which deals with quantities 
rather than with kinds, and with continuous variations rather than with fixed classes and categories. On the other hand, such a commercial subject as accounting is an incipient science of business working on much the same problems as formal economics, stated in much the same pecuniary terms, motivated by much the same concern for material gain, and thus far, to a significant degree, independently breaking its own way. Such a latter-day parallel must have its lessons for the academic economist.

But it is not necessary to go outside of economics in order to escape, at the start, the strait-jacket of conventionalized theory. It should be made possible to begin by exploring some part of the range of economic phenomena under the guidance of a teacher so completely a master of theory that he perceives it in its concrete manifestations. There should be much encouragement to thinking; little didactic supply of thought ready-made and stale. Then, if the student is competent, his own beginnings of economic theory will grow with his grasp of the widening field of inquiry. As his theoretical scheme expands and takes form, it can be put to the test of adjusting itself both to new information and to the theoretical systems of others. Once the student's own ideas have attained to some definiteness and organization the thorough study of economic doctrines offers stimulating contrasts; it can then be made critical, comparative, and altogether profitable. Before that stage of his career it might simply occupy his mental void and thenceforward obstruct any more spontaneous development.

This order of progress is at once most feasible and most appropriate in graduate study, where the emphasis is laid upon originality and constructive achievement. The graduate student will usually already have had quite enough didactic theory, as collegiate work goes nowadays. He will in most cases have an aptitude for his special work. He must have able teachers; but, granting him this essential, he should recognize theoretical implications in whatever he investigates. Economic truth need not be authentically revealed to him on his initiation to graduate standing. Gradually, and conformably with his own powers of reasoning, it will reveal itself.

The purport of these rather scattering paragraphs may be recapitulated in a few words. We err in thinking of economic 
theory as too much a thing apart. We are thereby led to the further error of trying to justify a theory remote from ordinary experience on grounds of traditional authority. We must rather seek to realize the theoretical significance inherent in systematized concrete factsto let theory express itself in scientific law and orderly method of investigation. The proper place for theory thus conceived is not only in every graduate course but in the whole range of economic scholarship.

University of Chicago

James A. Field 